\title{
LA ESCENA DEL CRIMEN: CIUDAD Y POESÍA EN LA TRANSICIÓN CHILENA ${ }^{\mathbf{1}}$ \\ The Crime Scene: City and poetry in Chilean Transition
}

\author{
Luis Valenzuela Prado*
}

\section{Resumen}

Un constante fluir de cauces heterogéneos convergen en las ideas de blanqueamiento y consenso en la transición chilena. Uno de estos cauces es el proceso por el cual el Estado intenta recuperar y dar confianza a la ciudadanía: la seguridad ciudadana que otorga la función de velar y de vigilar. No obstante, la presencia de un sujeto anónimo, criminal, cuyo tratamiento es presentado en el poemario Criminal (2003) de Jaime Pinos, hace mella en esta función. Así, la escenificación poética de este sujeto representa el desorden del consenso y la mancha del blanqueo.

Palabras clave: Transición chilena, poesía chilena, crimen, ciudad.

\section{Abstract}

A permanent flow of heterogeneous stream converge into lightening and consent of Chilean transition. The Government represents one of the streams, as regards to recover and increase the citizenship confidence; citizenship security, that grants the look after. Nevertheless, the presence of an unknown subject, Criminal (2003), who's treatment is presented in Jaime Pinos, collection of poems, makes an impression of this function. The poetic dramatization of this subject represents the chaos of the consensus and the spot in the white.

Key words: Chilean Transition, Chilean Poetry, Crime, City.

\section{INTRODUCCIÓN A LA ESCENA DEL CRIMEN}

Durante la transición chilena, el hecho de contar con un enemigo permite al Estado $^{2}$ asumir la función de velar por la seguridad ciudadana. Este enemigo habita la

\footnotetext{
${ }^{1}$ Este artículo forma parte del Proyecto Fondecyt $\mathrm{N}^{\circ}$ 1085255: "La ciudad en la poesía chilena posgolpe", financiado por el Fondo Nacional de Ciencia y Tecnología, Fondecyt, dirigido por la investigadora Magda Sepúlveda.

${ }^{2}$ La transición chilena presenta un constante fluir de cauces y hechos heterogéneos que emanan a comienzos de los noventa. Carlos Orellana (1999) cita una variedad de sucesos con los cuales es tejida la memoria nacional y la globalización: conviven secuestros y asesinatos con la fiesta deportiva; es blanqueada la imagen de un nuevo país, pero también son cerrados varios medios de prensa. Dos son los conceptos que resumen la transición: consenso y blanqueamiento. La dictadura buscó erradicar la memoria, y la Concertación quiso "hacer de la reconciliación un instrumental de olvido" (Eltit, 2000:30). Además, es decisiva en la época "la compulsión al olvido" (Moulian, 1998:31). La transición sentó sus bases en un consenso que "apagó" el "tratamiento de temas de sociedad pendientes como la tolerancia, el espíritu laico, el pluralismo, la objeción de conciencia, los derechos de las minorías, las diversas discriminaciones" (Otano, 2006:257). Se erige una estética oficial de la celebración festiva y ecuménica, por ejemplo, la fiesta en el Estadio Nacional después de
} 
ciudad y la inquieta, es una figura del crimen de la cual dan cuenta algunos poemas y poemarios (1988-2008), ${ }^{3}$ que configuran una escena poética del crimen. Un sujeto anónimo, ${ }^{4}$ una figura criminal desmarcada de la tradición literaria chilena del bandolero que se articula en medio de procesos de configuración de nación donde "los bandidos son personajes que usan la jerga huasa, también son sufridos, valientes y circunspectos" (Subercaseaux, 2007:138). Es un bandido pintoresco, cuyos actos terminan recibiendo la complicidad del lector y de la sociedad, en una literatura que prefiere "las hazañas y la leyenda romántica a la descripción o enjuiciamiento de crímenes y atrocidades" (Avaria, 19972). Eric Hobsbawm (1976) distingue al bandolero social, especie de héroe levantado por la sociedad campesina, del hampa criminal citadina. Este último evidencia discursos y problemáticas de la urbe, la que no lo erige como héroe.

¿Por qué es representada esta escena criminal? ¿Qué rasgos citadinos la configuran? ¿Qué aporta la poesía al escenificar el crimen en la transición? ¿Cómo se hace cargo Criminal de esta realidad compleja? El crimen ocupa gran parte del espacio poético de esa época. Espacio, "cruzamiento de movilidades" (De Certeau, 2000:129), donde el crimen es representación cotidiana y urbana que atañe a la ciudad. Si bien el crimen es evidenciado tanto por las instituciones de poder como por la poesía, las primeras lo enfatizan, ofreciendo ser quienes lo combaten, y luego, garantes de seguridad; mientras la segunda, lo encarna en forma diferente, desde la crisis que provoca. Lo representado es una escena ficcional que apuesta por un habitar urbano, la cual puede ser leída como "relato", a partir de De Certeau, teniendo una naturaleza delictiva: "Si el delincuente sólo existe al desplazarse, si tiene como especificidad vivir no al margen sino en los intersticios de los códigos que desbarata y desplaza, si se caracteriza por el privilegio del recorrido sobre el estado, el relato es delincuente" (2000:142). El relato atraviesa escenas, y el delincuente atraviesa la escena literaria y citadina. El crimen interviene escenas y se hace poesía.

Durante la transición, el neoliberalismo realiza un aporte esencial a esta escena $^{5}$ delictiva. ${ }^{6}$ Surge una disputa implícita y cómplice entre el Estado y la

que Patricio Aylwin asumiera la Presidencia de la República, en la que predomina "el espíritu del consenso" (Merino, 1998:687) que intenta amalgamar y limar diferencias.

${ }^{3}$ El año 2009 aparece el poemario Whitechapel (Santiago: Ediciones Das Kapital), de Camilo Brodsky, cuyo eje temático también es el crimen.

${ }^{4}$ En oposición a rostros como los de Augusto Pinochet, Osvaldo Romo, Luz Arce y Manuel Contreras.

${ }^{5}$ Noción de escena pensada desde la sociedad del espectáculo (Debord, 2000) relacionada con la escena observada a partir de los cuadros de vida y escenas mediáticas de Sarlo (1996), vista desde el teatro, en tanto "alude a la entrada o salida de un personaje del escenario" (Franken y Sepúlveda, 2009:11).

${ }^{6}$ La delincuencia aumenta en estos tiempos. Para Dammert el aumento de la criminalidad es un fenómeno global (2005:9). En el Chile de los noventa disminuye la pobreza, pero aumenta la acumulación de riquezas en los sectores del primer decil, lo que incrementa la desigualdad y el consumo (Portes y Roberts, 2005:58) lo que conlleva un aumento de la delincuencia, proporcional con la preocupación ciudadana por el tema (Dammert, 2005:24). 
derecha por el discurso de la seguridad ciudadana y la delincuencia. ${ }^{7}$ Esto se suma al miedo e inseguridad citadinos hiperbolizados y a los discursos enunciados desde el poder - Estado u oposición - sin desestimar el apoyo de la prensa. Para Moulian, la Concertación optó por adherir el tema de la delincuencia, a riesgo de proyectar la imagen de autoridad superada y sobrepasada $(2000: 134){ }^{8}$ la paradoja radica en que "los artífices de la sociedad neoliberal lanzan gritos de alarma por el aumento de la delincuencia que es una resultante, por supuesto no deseada, de su propia obra" (2000:137).

Así pues, hace sentido la propuesta de este artículo en cuanto a una supuesta conveniencia política de presentar el tema delictivo, el cual deviene figura criminal, representada por la poesía chilena que mancha la escena pulcra escenificada por el Estado y por la oposición. Si bien este artículo no busca ampliar la definición de la transición se espera hurgar en temas que manchan el blanqueamiento de la transición que viene dado por una matriz histórica ${ }^{9}$ de limpieza cultural. En dictadura, esta idea es desarrollada a partir de la "metáfora de la higienización", presentada como "una forma de violencia epistémica" que permite "erradicar lo sucio" como parte de "un problema territorial" (Sepúlveda, 2008:68). Durante la transición viene a desmanchar las sombras de la dictadura y a proponer acuerdos que no desentonen el proceso democrático. ${ }^{10}$ En sus discursos, tanto el Estado como la oposición, buscan alzarse como garantes de la seguridad social y citadina. De este modo, es creado y representado un enemigo que, al ser controlado, termina siendo parte del discurso blanqueador, que al blanquear implica mancha ${ }^{11}$ velada. Jaime Pinos derrama sangre en la ciudad, testimonia un momento

\footnotetext{
${ }^{7}$ La delincuencia es "problema crucial" (Moulian, 1998:143) y principal preocupación desde el regreso a la democracia (Dammert, 2005:7) contexto en el cual el Estado y la oposición chilena, surgen como garantes de la seguridad.

${ }^{8}$ A fines de esta década, la delincuencia es tema central en los programas de gobierno de Lagos y de Lavín. Además, el gobierno aumenta los recursos para Carabineros e implementa diversos programas de seguridad pública. Especial importancia adquieren los institutos ligados a la oposición, como Libertad y Desarrollo y Fundación Paz Ciudadana.

${ }^{9}$ Blanqueamiento con base en la categoría de la "raza chilena", contextualizada por la "emocionalidad de la patria" en el Centenario (1997:79), por el darwinismo que destaca la "selección del más apto y de la lucha por la supervivencia" y de la eugenesia que aplica las leyes de la herencia al cuidado y perfeccionamiento de la raza" (Subercaseaux, 2007:80).

${ }^{10}$ Para Eltit, en los años noventa tanto "simulacro" como "pacto" son operaciones políticas que nos hacen entrar en "una fórmula domesticadora" y ser parte de una convención (28). Moulian propone "sospechar del discurso de la reconciliación" (2000:26) visto en el "duelo" que intenta erigir la Concertación desde el cruce del Informe Rettig y del iceberg en Sevilla, fracasos, ambos, ante el silencio y no reconocimiento de culpas desde las FF. AA.

${ }^{11}$ En La historia de la sangre, de Alfredo Castro, uno de sus personajes dice que la sangre permite testimoniar. En el disco Aerolíneas (1999), el grupo Makiza expone una sangre testimonial: "Algunos escriben con sangre la historia / Y otros con poemas..." e identitaria: "El mundo es un gran Arca de Noé / Y si yo he nacido afuera estoy orgullosa / Y si tengo sangre indígena, mejor, porque es hermosa”. El documental Reynalda del Carmen, mi mamá y yo (2005),
} 
post-dictadura, desde la transición. Así, la representación poética del sujeto criminal asume y proyecta aristas que devienen mancha, desde el crimen y desde el sujeto que mancha el discurso blanqueado. Así, el criminal deviene figura del caos que desordena la escena citadina y de la transición; es la figura que ensucia y que está fuera del margen de control.

\section{LA ESCENA DEL CRIMEN EN LA POESÍA DE LA TRANSICIÓN CHILENA: 1988-2008}

Para Francine Masiello, en las transiciones - de tendencia neoliberal- la literatura y el arte "cultivan la contradicción, revelando las tensiones entre el pasado no resuelto y el presente, lo oculto y lo visible" (2001:16). La poesía que representa el crimen cuenta con una ciudad de fondo; se trata de una poesía que convoca escenas de violencia veladas, sea desde su ejecución, desde su observación como espectáculo debordiano, ${ }^{12}$ o como espectáculo que "desde distintos ángulos se 'muestra' para mover el ánimo o los afectos" (Subercaseaux, 2000:207). Una violencia que mancha con sangre la ciudad cotidiana y la ciudad blanqueada de la transición, permitiendo al Estado jugar, a la vez, el rol dual de vigilante y garante de seguridad ¿Qué representación del crimen hace esta poesía durante estos años?

La revisión de algunos poetas del periodo de la transición permite delinear ciertos matices de la escena en cuestión. Carmen Berenguer, con Naciste pintada (1999); Yanko González, con Metales pesados (1998); y La insidia del sol sobre las cosas (1997), de Germán Carrasco, aseguran una base poética con ciertos matices en el tratamiento del crimen, base que ayuda a revisar sus cimientos en la poesía, en especial en el poemario Criminal (2003) de Jaime Pinos, tendiendo una red poética de vínculos, posibilitando la representación de la mancha criminal en tiempos de una blanca transición. ${ }^{13}$

Cuando Óscar Galindo lleva a cabo una revisión de la poesía chilena de fines del siglo XX, pone énfasis en los procesos de "mutación disciplinaria" en los que ésta se sume, es decir, "perspectivas transdiciplinarias" que han ido desestabilizando las "distinciones tradicionales entre lo literario y lo sociológico"14 (2003:193). Es

de Lorena Giachino, muestra una escena donde es cuestionado el trabajo de la justicia en tiempos de dictadura. La narradora enuncia su discurso mientras se muestran los pasillos del Poder Judicial. La limpieza que hace el personal externo del aseo, intenta limpiar el accionar judicial que no vio la sangre que manchó/testimonió el país.

${ }^{12}$ En 1994, Debord confirma su idea de "espectáculo" a partir de lo que "ha sucedido a lo largo de los últimos veinte años, el cambio más importante de la sociedad del espectáculo reside en la propia continuidad del espectáculo" (2003:19).

${ }^{13}$ En la poesía chilena el crimen tendrá un interesante antecedente en la Lira Popular, en poetas como Rosa Araneda, Daniel Meneses, Adolfo Reyes y Juan Bautista Peralta, entre otros. Cfr. Maximiliano Salinas Campos. Versos por fusilamiento. El descontento popular ante la pena de muerte en Chile en el siglo XIX, Luis Hachim Lara. Carlos Pezoa Véliz: alma chilena de la poesía (2005).

${ }^{14}$ También entre lo literario y "lo político, lo antropológico, lo historiográfico, lo culto y lo popular; lo central y lo periférico; las marcas identitarias locales, barriales o sexuales, estableciendo el 
evidente que en esa mutación pueda enmarcarse el desplazamiento hacia la crónica roja u otros géneros referenciales o literarios, realizado por Pinos y Berenguer. Desplazamiento, de una u otra forma, crítico con la poesía y sus formas, lo que provoca cierta "inestabilidad e hibridaje de los saberes y disciplinas, de los métodos de conocimiento de la realidad, así como de la construcción del sujeto autorial" (2003:194).

En Naciste pintada conviven tres géneros, el biográfico, el epistolar y la crónica roja. El poema "Ruinas" parte desde el recorrido citadino de la hablante, "la noche no es la noche ideal / romántica de los cantos versallescos" (14), sino la de los parias, del criminal nocturno: "La noche de la novela triste es cuando sus luces / se apagan y aparecen las sombras criminales" en toda la ciudad. Estos versos son un fragmento de la ciudad que busca escenificar Berenguer. Una escena citadina de una "novela" que refleja el carácter ficcional y metaliterario del poema: "en este libro / en medio de estas páginas". En tal libro, la "ciudad es protagonista fundamental y expresa la idea de nación estrellada" (Calderón, 2006:44) donde la ruina implica un pasado que se opone a tiempos prósperos. Luego, el poemario prosigue con el perfil sensacionalista-rojo del delincuente dado por el Diario $L a$ Cuarta: "Notorio aspecto de malandrín, sucio, moreno, delgado, mal vestido, de cabello largo desgreñado y duros rasgos faciales..." (30). La ciudad se transforma en "un discurso de lo minoritario" y devela "zonas de abandono, de olvido" (Calderón, 2006:43). Berenguer se muestra distante de la masa, la voz poética observa y reconstruye el paisaje, esboza a este criminal anónimo; esboza la figura de la Chinoska (Clara de las Nieves Morales) y revisa su caso cuando de tres puñaladas asesinó a su pareja; relaciona el día del crimen, 23 de abril de 1990, con los primeros "pasos balbuceantes de nuestra democracia" (150); reconstruye el "ambiente democrático" de las palabras de Aylwin, el episodio de la pérdida del ojo del General Leigh, las ventas del single "Un hombre secreto" de Myriam Hernández, y el matrimonio de Cecilia Bolocco. En fin, da cuenta de un ambiente de cauces heterogéneos que contrasta con la "noche de amor" que terminó en un sangriento crimen pasional. En ambos poemas, los criminales son parte de una escena citadina oscura oculta, una escena que atenta contra el blanqueado "ambiente democrático", lo mancha. Para Kirkpatrick: "El proyecto de Berenguer parece ser el de enseñar la otra cara de la moneda, la del Chile impuro, el Chile nocturno que vive todavía a pesar de los aguaceros" (79).

Por otra parte, Metales pesados de Yanko González, representa una escena violenta con un hablante que forma parte de ella: "Fumándonos Punto Rojo / Reducimos a fierrazos / Al matón de la puerta" (11). Las drogas componen la escena del poemario y condicionan a los personajes: Zipeproles, con un sujeto "in(h)alado" (45), un sujeto "volado" y "sin alas". También está presente el alcohol, el "pisco de 40"

espacio de la diferencia como lugar de semiotización, en un régimen textual marcado por la hibridación, la mixtura y la pluralidad inestable" (Galindo, 2003:193). 
(11) o "mientras se echa el cuarto de pisco en una tráquea" (41). El hablante no llega ni a la reivindicación, ni a la crítica al sistema. Sólo es mostrado el fragmento, el lugar violento, la urbe, ahora desde urbe provinciana, doblemente marginada. El poemario, sobre todo la primera parte que recurre a un "lenguaje de sectores marginales, cercanos a la delincuencia" (Neira, en línea), construye lo colectivo y lo violento: "Te violamos Pat'e cumbia / Nosotros los roba-tapa de los esteichon [...] / te hicimos colectiva en el miadero" (12); "pero aquí igual somos pacíficos / igual he clavado / he chantado" (13); "porque igual le pegamos su puntazo" (14). Colectiva construcción, —esa de los "robatapa de los esteichon", "somos los más locos" (28) — la de quienes distorsionan su cuerpo con droga/alcohol y violentan los de otros, de cualquiera que sea, "a fierrazos" o violando. En el poemario de González no hay acecho, no hay extrema tensión, sino una construcción antropológica, desde las bases académicas del autor. Hernán Neira sostiene que la poesía de González "tiene una posibilidad de lectura que no es sólo poética, pues también se abre, sin contradecir la anterior, a una lectura etnográfica sobre sectores marginales urbanos" (2000). Una lectura que anticipa el acercamiento a Criminal que escenifica otros sujetos que forman parte de un conjunto que mancha y altera el orden de los tiempos que se viven. Doble desplazamiento, ya que desde la provincia es asumido el margen y dentro de ésta, otro margen.

Finalmente, en La insidia del sol sobre las cosas, de Germán Carrasco, con un "estilo marcado por la prosa [...] el tiempo transcurre pausado y silencioso" (Atal, 1998:3), la escena criminal da color sangre a la ciudad. La escena propuesta de Carrasco muta, primero una escena como cualquier otra: "ni culpar a la noche de la traición, el crimen o de los últimos sucesos" (7); en "Block", se afirma que "Ayer, sin ir más lejos, alguien fue asesinado luego de un fracaso futbolístico" (20), o que el crimen se produce en el encierro citadino: "Ahí dentro, seguramente encontrarás muerto a Julián" (18). Finalmente, la muerte cotidiana deviene en muerte momentánea del hablante: "yo también — como Julián — / muerto, con otra, o esperándote" (19), y hacia el final la elegía, el funeral, el suicidio, la muerte: "Elegía De Hielo / Partitura De Réquiem"; "The crying shadow in the funeral dance" (74) o en "(Cada poema una elegía. / Cuando el poeta muere, una elegía / a sí mismo)" (81). El crimen cotidiano como ejercicio común de todos los días.

Los poemas de Berenguer, González y Carrasco permiten llegar a Criminal y a la representación directa de un sujeto con nombre y apellido: Roberto Martínez Vásquez (el Tila). Con el fin de abordar una realidad difícil de representar, Pinos reconstruye al Tila mezclando diversos trazos escriturales, abriendo perspectivas (en primera persona; científicas y poéticas en tercera persona) y tipologías textuales (cartas, encuestas, imágenes) de una configuración compleja del Tila. Al igual que Naciste pintada, "texto híbrido y heterogéneo" (Hernández, 2008:73) o Metales pesados, con su discurso antopológico-poético, también híbrido, en Criminal conviven textos, retazos útiles para representar una escena del miedo habitada por el sujeto criminal: un prontuario, la biografía, la referencia literaria, la escena de los 
medios, la imagen visual, la redacción de un informe psiquiátrico, el género epistolar y el testimonio del Tila y el poema final, con una voz más cercana al poeta. Los diversos trazos escriturales dan cuenta de las diversas posibilidades de abordar y representar al criminal.

\section{UN CRIMINAL ANDA SUELTO}

Si un criminal anda suelto y ronda la ciudad, otro Criminal entra en la escena literaria antes anunciada, ahora a partir del poemario de Jaime Pinos. Este poemario no renuncia al crimen, no intenta reconstruir la metáfora de su protagonista como el sujeto violento que, por antonomasia, encarna la violencia y el temor latente en la urbe, pasada ya una década de transición postdictatorial. El criminal es una figura que remece la escena citadina y blanqueada de la transición, es la mancha sin higienizar, fuera del margen de control. Mata, roba, viola. Pero Criminal no entra en el juego del combate a la delincuencia, por el contrario, asume al sujeto que no puede ser controlado, que escapa al orden, pero que, a la vez, sirve de coartada para que el poder mantenga su condición de garante de seguridad. El poemario da cuenta del criminal humano, víctima y victimario. Un criminal que anda suelto.

Para Patricia Espinosa, Criminal "es un libro polémico y con gran fuerza crítica, que nos enfrenta al crimen y al castigo como instancias competitivas" (17). Espinosa enfatiza el recurso de la primera persona del criminal, pero, también, los cambios de voz y perspectiva del "conjunto narrativo-poético". Por su parte, Luis Riffo pone de manifiesto el espectáculo que se monta en torno a una "figura maldita, cuya condena ya se había dictado desde el origen de su vida" (en línea). A la vez, Marco Antonio Coloma destaca lo "abierto y provocador" del poemario, lo que "delata a una sociedad que le teme a la locura, y que se obstina por barrer la suciedad bajo la alfombra. Criminal es el lado B del control, el estigma y la condena" (en línea). En cambio, Celedonio Torres releva la voz de Pinos como "una voz original, plena de realismo, clara y penetrante" (en línea). Esta panorámica crítica da cuenta de algunas lecturas que abre el poemario.

De esta manera, el Tila es el hablante en gran parte del poemario: Roberto Martínez Vásquez (conocido como el sicópata de La Dehesa, acusado de asesinatos, robos y violaciones, un sujeto que puso en jaque a la ciudad entre 1990 y 2002, años cruciales para la transición chilena), un sujeto que finalmente se suicida en la cárcel. Son ocho los poemas en los que la voz del Tila es reconstruida desde la primera persona, una suerte de simulación de la voz criminal: "Soy el que acecha. / El que anda por ahí, / merodeando, / agazapado entre las sombras, / oculto en lo más profundo de la noche" (7). Es un intento de configuración del sujeto acechante, que vigila desde las sombras de la ciudad, que emula la figura del Tila, la figura que intimida y que provoca. Pinos, cuando aspira a representar la voz del Tila, lleva a cabo un intento que entraría en tensión con la pregunta que hacen Spivak y Beverly 
sobre la representación de la alteridad. ${ }^{15}$ ¿Es la voz del Tila? Evidentemente es una construcción, es la escenificación estética de un criminal con referente real que deviene en personaje literario.

Desde el poemario, el "yo" representado se "autodefine" tal como —o cerca de - la imagen que la sociedad tiene de él. Con una enunciación en primera persona se muestra a ese hablante oculto entre las penumbras, transeúnte y vigilante espantoso de la ciudad. Una suerte de vigilante foucultiano a la inversa, un panóptico que vigila la ciudad. El Tila es el que acecha, el que está agazapado, el que se autodefine como: "el Gran Violador", "el monstruo", "el cazador y la presa". "Yo soy el que acecha. / Yo soy su miedo" (8). "Yo soy el que no tiene piedad. / Yo soy el implacable" (20), "Yo soy el que no tiene perdón / Yo soy el condenado" (39). Es la voz del sujeto que asusta y que está "Ansioso por iniciar las ceremonias de la cacería" (10). Un yo enfatizado, que persigue y espanta a otros ("ellos"), que asume a la vez, desde la voz reconstruida por Pinos, su lugar. El Tila profana y deshonra todo lo que para "ellos es sagrado" (7), es decir, el cuerpo inocente, asido, de la mujer/niña violada, el sueño "nunca más tranquilo, de las niñas inocentes" (7). Lo sagrado constituye también el hogar profanado. Distintas pruebas lo vinculan a la "zaga de ataques y violaciones / que aterroriza a la población" (11). Esa figura del yo entra en tensión con otros opuestos a él. El yo y el ellos El Tila caza y es cazado. Provoca dolor a otros como forma de catarsis y purga: "A veces el dolor es el único desahogo" (19), "La violencia fue mi estilo, / los golpes recibidos / mi principal influencia" (32). Provoca dolor a otros, pero su actuar es desarrollado como un suceder de otro dolor provocado al mismo criminal. Es decir, se plantea la idea de un crimen como producto de un vicioso círculo social. El criminal da y recibe, dualidad que surge por cuanto el poemario desarrolla la idea de ver al criminal como sujeto que provoca, pero es provocado, que hiere, pero que es herida en sí mismo. Es un sujeto paradójico que surgiría de la contradicción misma.

El Tila deviene en una figura que prolifera por los aires de la ciudad, que simboliza la dosis perfecta de violencia que necesita durante la transición para reemplazar otra violencia: ésa de la dictadura. De este modo, el discurso de la seguridad ciudadana triunfaría al controlar los hilos de la escena del espectáculo, pero a la vez, la presencia del Tila evidencia la fragilidad de esa escena, y la complejidad para abordarlo y representarlo.

Por otra parte, la escritura emerge como otro tópico literario trabajado como forma de liberación del sujeto: nuevamente de purga. En "Discurso de las bellas artes", el hablante dice: "Yo soy el escritor maldito / Yo soy el peor de los libros" (33) y, a su vez, El Tila es representado y leído desde la poesía. "No pude ser feliz, ello me fue negado, / pero escribí" (32), versos al modo de la escritura vivencial de Lihn, pero, aquí, en proceso de escritura maldita, una poesía crónica, agonizante, dura y

\footnotetext{
${ }^{15}$ Pongo énfasis en la condicionalidad de la afirmación, ya que la subalternidad que se propone es discutida por Beverly (2004) y Spivak (1998) en otros espacios de la subalternidad.
} 
directa, como la realidad representada. El poema aludido vuelve sobre la sangre, la que deviene en tinta vivencial que esboza y da trazos de su vida: "La letra con sangre / fue la historia de mi vida / el delito / mi género predilecto / el horror / una poética real refrendada en cada una de mis obras" (32). La vivencia del criminal se traduce como experiencia estética, como metáfora de la violencia corporal que ejecuta y recibe el Tila, este personaje paradójico.

El género epistolar explica algunas de sus motivaciones, con dos supuestas cartas enviadas por el criminal a los poderes del Estado: al "Señor Ministro del Interior" y al "Señor Juez". Confesiones abiertas mediante una enunciación apostrófica. Al Ministro, con un tono increpador: "Usted habla de mi vida / como si hubiese elegido dedicarla a delinquir. / Pero se equivoca. / Yo quería hacer algo con ella" (27). Su carta reprende, escenifica el prejuicio, asume el deseo fracasado: "Usted habla de crimen / Como si fuese un vicio que algunos practicamos [...] / Pero se equivoca. / El criminal no nace, se hace" (27). El discurso epistolar facilita la conexión con quienes ostentan el poder. Un intento dialógico frustrado, sin respuesta. Desde el margen se clama, desde el centro no se oye. Se opone, a la vez, el espacio oficial "Desde las alturas del poder" (28); frente al "acá / en los bajos fondos" (28). Surge así la culpa y la recriminación al otro que lo tatuó: "Yo soy la cosecha. / Yo soy lo que sembraron" (14). El criminal no nace, se hace, no es un criminal por naturaleza, ${ }^{16}$ es producto del accionar de la sociedad de la cual es enemigo y con la cual no pudo suscribir un pacto o, tal vez, lo rompió a temprana edad.

\section{RETAZOS PARA REPRESENTAR UN CRIMINAL}

Retomando a Hernán Neira, respecto a Metales pesados, habría que asumir a Criminal no sólo desde la lectura poética. Por ejemplo, una lectura desde la crónica enriquecería al sujeto literario, complementándose con el sujeto público. De esta forma, al identificar y revisar las diversas tipologías textuales que configuran la escena, habría que sostener que en Criminal la poesía, en sí, es apreciada como una poesía crónica, con el sentido de agonía presente; y de una crónica poética, como crónica roja periodística que ahonda en los hechos de manera secuencial en que ocurrieron. La "crónica se organiza en un relato mediante la ulterior ordenación de los hechos como componentes de un 'espectáculo' o proceso de acontecimientos, que se supone tiene un comienzo, medio y fin discernibles" (White, 1992:16). Para Leonidas Morales la crónica ha estado destinada "a contar episodios de la vida cotidiana o de la actualidad, asumiendo cada cronista un determinado punto de vista" (2009:229). La crónica se encontraría en "una situación de marginación dual [...], en un espacio

\footnotetext{
${ }^{16}$ Idea que dialoga con dos matrices culturales de los años noventa. Una, el Club Deportivo Universidad Católica propone el eslogan: "Porque en Chile, un campeón no nace, se hace”. Otra, la película Nature Born Killers, de Oliver Stone, pone énfasis en lo intrínseco de la maldad de sus protagonistas.
} 
fronterizo entre literatura y periodismo" (Henríquez, 2008:114); recrea atmósferas y personajes, transmite noticias y denuncias, recurre a diversas herramientas para representar la caótica realidad. Al recuperar la crónica roja, Criminal reconstruye el orden temporal de los pasos del Tila, una crónica escrita y agónica de una ciudad/sociedad.

Otros poemas, titulados sin metáforas ni figuras retóricas, como "Prontuario" e "Informe psiquiátrico", pueden ser leídos como textos de fuente referencial. "Prontuario" da cuenta del recorrido cronológico de la maldad de este criminal; 1990 y 2002 son años de transición: asalta, es detenido y puesto en libertad, mata, es condenado, cumple condena, descuartiza, viola, atemoriza a la ciudad. "Pruebas de ADN lo vinculan, entre otros treinta sospechosos, / a la zaga de ataques y violaciones / que aterroriza a la población" (11). El poema comienza con el verso: "Se abre la cacería", usando la misma palabra que antes nominaba la acción del criminal, lo que da indicios de una reconstrucción crítica que ve en el Tila y en la policía, la figura del cazador que persigue y ataca a su presa. Dos acepciones para dos protagonistas de la ciudad con diferentes roles.

"Informe psiquiátrico" intenta abordar científicamente la enfermedad mental del criminal. Una junta médica, "cuatro facultativos" (25), aplican tests y entrevistas durante tres meses, llegando a la conclusión de que el criminal: "es plenamente imputable" (25). Los exámenes neurológicos no arrojan resultados positivistas: "en cuanto a detectar / algún factor hereditario / que pudiese explicar su conducta criminal" (25). No hay razón científica que contente a quienes buscan respuestas concretas. El informe psiquiátrico "consigna el maltrato físico y el abuso sexual reiterado / a que fue sometido durante su infancia" (25), experiencias que "lo habrían llevado a reproducir con sus víctimas / el papel del agresor" (25). El "informe", y todo lo que implicaría su carácter científico, arroja, como resultado y conclusión, que el Tila se declara bisexual, posee "un coeficiente intelectual superior al promedio" (25), y es adicto a varias drogas. Este "informe", es el resumen de otro supuesto informe de "once carillas", las que "establecen que el reo posee una personalidad antisocial de carácter psicopático", lo que no afectaría su juicio "ni su percepción de la realidad" (26), "No estaba loco, / [...] El Criminal sabía lo que hacía. / De nada servirían en su caso / Los asilos, / La farmacopea, / Los electroshocks "(26). De nada serviría el encierro y el castigo: "Lo suyo es una gangrena que ha ganado todo el cuerpo, / un cáncer que ya no puede extirparse, / una piedra imposible de extraer (26). Estos últimos versos develan un distanciamiento del carácter científico y preciso de un informe. Tal como en "Prontuario", "cacería" homologa la acción del Tila con la de los poderes que lo quieren cazar, en este "informe psiquiátrico", "gangrena", "cáncer", "piedra", son metáforas del Tila o, desde una mirada más amplia, de la figura del criminal bosquejada por el discurso reconstruido en el poemario, no desde la voz del criminal, sino desde quienes lo cazan y analizan, incluso de quien, en cierta 
forma, lo pone en escena. Además, está claro que ninguna espacialidad ("asilos") ni estrategia ("farmacopea" y "electroshocks") logran controlar y someterlo.

Otro cruce de tipologías textuales proviene de la literatura, dando tintes del policial negro y de citas literarias criminales. En el primer caso, el cerco cerrado deviene reconstrucción policial en "Puzzle policial", un franco diálogo con el género negro: "Una colilla de saliva del atacante / encontrada en una de las escenas del crimen. / Evidencias orgánicas / halladas en una hoja de papel" (12). Sin detectives, el poema recurre explícitamente al trabajo policial para resolver el "puzzle". Entonces ¿Por qué no pensar un poemario policial? Esto daría una vuelta a un género históricamente cobijado por la narrativa. No obstante, tal guiño es subvertido en la figura de quien ejerce el crimen. En él no hay arte criminal, no hay abuso de poder, en cuanto a jerarquías sociales. Es un paria que asusta. La diferencia es su poder. Tampoco es abordado como el sujeto popular pintoresco, relacionado con la tradición literaria del bandido que transita por la ciudad o el campo, siempre recubierto por una aureola de leyenda y con cierta complicidad de su entorno y del lector. El Tila tampoco carga con la idea de identidad que Subercaseaux ve en otros personajes de la literatura; es un sujeto paria, no pintoresco, que está más cerca de Eloy, de Carlos Droguett, o de El chacal de Nahueltoro, de Miguel Littin. ${ }^{17}$ El Tila es el margen, por cierto, de su condición, antes autodefinida por él mismo, de "criminal" o de "gran violador" que, luego, pasa a ser enunciada por otra voz, con los eufemismos de "autor de los ataques" o de "culpable". Sin embargo, "fuentes judiciales" informan que la captura no fue "el resultado de las pesquisas", una recompensa para delatarlo o "el indulto presidencial / como precio por su cabeza". El puzzle permite comprender que la escena no está compuesta sólo por el victimario y por la víctima, sino también, por sujetos delatores y agentes de la justicia que operan gracias al criminal, dando cuenta de un cruce de cacerías que mutan de manera constante en medio de una especie de ciudad antropófaga.

El género epistolar, ya citado en las cartas a los poderes públicos, está inscrito en el plano de lo que Leonidas Morales llama "cartas de petición”, vinculadas con el golpe militar de 1973 y con una tradición que data de tiempos coloniales. No obstante, las de Criminal no son "cartas abiertas", con publicidad, "lo que en ellas se da es más bien un fenómeno de hibridez, un cruce entre lo privado y lo público" (Morales, 2001:40). Pinos, al imitar las cartas de petición, en este caso dirigidas a los "poderes", transita por los límites de lo público y lo privado, donde un emisor, lo privado, solicita de manera directa algo a un receptor, jerarquía pública. El primero intenta captar la "benevolencia" del segundo. Observemos que las cartas del Tila

\footnotetext{
${ }^{17}$ En "La escena del crimen: Matrices y diálogos del poemario Criminal de Jaime Pinos con la tradición literaria y cinematográfica chilena" (Congreso de poesía "Chile mira a sus poetas", 2009), desarrollo vínculos con Naciste Pintada, de Berenguer; Eloy, de Droguett, y El chacal de Nahueltoro, de Littin.
} 
tienen un contenido crítico. La dirigida al "Señor Ministro" termina diciendo: "Desde las alturas del poder, / nunca podrá siquiera imaginar / lo que es la vida / acá / en los bajos fondos" (28). En la otra, increpa al "Señor Juez": "Déjeme decirle que sus últimas resoluciones me tienen muy molesto" (29) pero termina agradeciéndole algunos gestos: "quiero agradecerle que me haya tratado / como a un ser humano. / No como a un animal peligroso / o a un monstruo de feria" (29). Tanto la "petición", desahogada y crítica, como el agradecimiento, ponen énfasis en cierto intento por revocar la condición del subalterno que logra encarar, por escrito, a la autoridad.

En Criminal también aparecen los medios de comunicación, esos "medios que viven de los miedos" (Martín-Barbero, 2002:21). En la encuesta pública, en las luces que enfocan al criminal y lo espectacularizan, en consonancia con la idea de Debord, el criminal es metáfora del miedo citadino, es el monstruo no dictador ${ }^{18}$ que proyecta una imagen pavorosa y anónima. Es un rostro anónimo que de un momento a otro es el centro, sin buscar serlo. De ahí que es leído como "rostro" opuesto de las campañas publicitarias entorno a la Seguridad Ciudadana — una de ellas protagonizadas por el dibujo animado llamado a don Graf - es la figura perfecta para reproducir el miedo. En ambas es el centro de atención: "Como un verdadero rock star, / El Criminal en todos los noticieros / El Criminal en todas las portadas" (17). Desde un margen llega a un centro, intimida, las luces se proyectan hacia él, es la figura que está en boca de todos, el protagonista del espectáculo.

La ciudad permite situar el poemario y al Tila. Es el espacio del miedo, no del mall ni de globalización. Él, agazapado en terreno de nadie, cuenta con un plano de Santiago, una "cartografia secreta": "Un mapa personal del horror / trazado de sangre y de muerte / sobre el plano de la ciudad" (22), una construcción situada en las antípodas del discurso de la transición que no lo reconoce como hijo putativo. El mapa es una "escena totalizante donde elementos de origen dispar se conjuntan para formar un cuadro de un 'estado' del saber geográfico" (De Certeau, 2000:133). Representar el territorio es apropiárselo, no como un calco, sino como una construcción, con él, el mapa comparte el "ser proceso, producto, proyecto", llegando a manifestar "el territorio inexistente con la misma seriedad que el real" (Corboz, 2004:31). De ahí que la ciudad —el barrio Alto, el Penal y la Cárcel de Puente Alto, el hospital José Horwitz Barak - y la imagen de un mapa, sean esa "escena totalizante" y la representación de un producto.

A la vez, cobra relevancia el dispositivo visual, la imagen de infancia en Reumén (Valdivia) publicada por El Mercurio cuando el caso del Tila estaba en escena. La imagen permite abrir la palabra escrita a la imagen y a la infancia. El Tila "piensa en cómo habría sido todo si hubiera tenido / una infancia normal" (Pinos, 38). La fotografía proyecta un desplazamiento vivencial y citadino en el

\footnotetext{
${ }^{18}$ Simunovic Díaz (2006) habla de la necesidad de contar con enemigos cuando caen las dictaduras. Chile, por ejemplo, se convierte en "monstruo" durante la dictadura, monstruo encarnado por la figura de Pinochet.
} 
actuar del criminal, luego es reconstruida por el dibujante Christiano en la portada del poemario, entablando un interesante vínculo entre texto y paratexto. ${ }^{19}$ Lo visual se ve, además, en el fragmento del plano de Santiago (Publiguías), que el hablante del poemario dice fue encontrado en el domicilio del Tila. El plano aparece intervenido con un ají cacho'e cabra atado a la ciudad (un trozo de ésta), con hilos afirmados con clavos enterrados en el plano, y una hoja de gillette que intenta cortar los cables o el ajímapa, una hoja que interviene el "saber geográfico" de la ciudad y la escena literaria. La visualidad presente en Criminal se adentra en la problemática de lo intermedial, de la relación imagen-texto en el arte, donde, según lo planteado por Mitchell, tanto el texto como la imagen son artes compuestas, cuyo problema se desarrolla "dentro de cada una de las artes o medios individuales. En resumen, todas las artes son 'compuestas' (tanto el texto como la imagen); todos los medios son mixtos, combinan diferentes códigos, convenciones discursivas, canales y modos sensoriales y cognitivos" (88). Esta complejidad da cuenta del cómo abordar al Tila, en tanto sujeto también complejo, como recurso discursivo que abre sentidos de los textos, como un trazo escritural que complementa su representación y escenificación.

La escena citadina deviene en encierro. La muerte sembrada por el Tila en la ciudad se transforma en su muerte encerrada en la escena final de Criminal, en un sentido cinematográfico, dado por el tratamiento descriptivo y visual: "Se vestirá con cuidado / hasta quedar en camiseta y calzoncillos / en medio de la oscuridad absoluta" (42). El rito es descrito junto con los pasos a seguir por oficiante: "Desconectará el cable de la máquina de escribir eléctrica. / Atará un extremo alrededor de su cuello. / Y el otro a los barrotes de la minúscula ventana. / Cuatro minutos, / según el cálculo de los forenses / tardará El Criminal en morir" (42). El detalle visualiza desde la palabra. Luego, es evidenciado el ojo observador: "A continuación, / el ojo ciego de la cámara / registrará los primeros destellos, / la puerta que se abre, / los rayos de luz de las linternas / irrumpiendo en la oscuridad (43). Cuatro minutos de soledad en que el criminal se aleja para dejarnos supuestamente tranquilos. Si la cárcel era parte del control ejercido por el Estado — garante de la seguridad - el suicidio trisará ese control, y el castigo perderá su rol.

Por último, en el poema "Réquiem", surge una tercera voz, que pertenecería al poeta, ampliando sus perspectivas: "Señor, / bien lo sabes, / el signo de los violentos / marcó su breve paso por este mundo. / Su mala vida / fue el dibujo de un reguero de sangre" (45). La supuesta voz del poeta/hablante resume la "mala vida"

${ }^{19}$ Genette sitúa el texto literario y el paratexto en distintos planos. Así, afirma que la obra literaria consiste en un texto que "raramente se presenta desnudo, sin el refuerzo y el acompañamiento de un cierto número de producciones, verbales o no, como el nombre del autor, un título, un prefacio, ilustraciones, que no sabemos si debemos considerarlas o no como pertenecientes al texto" (2001:7). El paratexto corre en paralelo o fuera del texto literario, es "aquello por lo cual un texto se hace libro y se propone como tal a sus lectores, y, más generalmente, al público. Más que un límite o una frontera cerrada, se trata aquí de un umbral" (2001:7). 
del criminal y pide por él: "Los que vivimos en esta ciudad enferma, / Como lobos y ovejas, / Bajo el imperio sangriento de la depredación. / Los que lo aborrecemos / porque amamos la muerte, / a Ti, Señor, te pedimos: / ten piedad de su alma, / ten piedad de nosotros". Pide clemencia por quien es la "cosecha" de lo que la sociedad sembró: "Yo soy el que no tiene perdón. / Yo soy el condenado" (39). Luego el suicidio: "No verá los titulares ni lo especiales de televisión / anunciando su suicidio / No verá al abogado defensor culpando al sistema social / [...] No verá al ministro excusando la negligencia carcelaria para hacer cumplir la ley" (43). No verá el espectáculo. Muere el criminal, pero continúa en escena.

\section{CONCLUSIÓN}

El constante fluir de cauces heterogéneos durante la transición, deja en escena ciertos recodos oscuros difíciles de abordar; puntos ciegos que omiten bultos, sujetos, temas; en el caso de este artículo, la figura del criminal. La representación de su figura y la escena poética que habita, pone de manifiesto una huella que ensucia el blanqueamiento del período, que violenta y derrama sangre en la ciudad, testimoniando un momento vivido por el país. Criminal no entra en el juego del combate a la delincuencia de la transición, tampoco en el de personaje literario pintoresco; por el contrario, asume al sujeto que no puede ser controlado. Al representar la escena del crimen, el poemario viene a manchar el discurso higienizado y blanqueado del espectáculo montado por el Estado y por la oposición. Si bien el criminal es su enemigo perfecto, la escenificación poética da cuenta de un sujeto que no puede ser controlado, lo que impide erigir a los entes ya mencionados como garantes de la seguridad civil.

El criminal que anda suelto es la figura que caotiza su entorno, y entra en tensión con la sociedad. El Tila es víctima y victimario. Ataca y es atacado. Provoca dolor a otros como forma de catarsis y de purga. Hacia el final del poemario, la representación del suicidio del criminal hace volátil la presencia del cuerpo encarcelado. Si los discursos de la seguridad ciudadana giran en torno al castigo y al encierro, el suicidio impide ese objetivo. De ahí que sea pertinente el gesto de la poesía de hacerse cargo de esa figura compleja de abordar. Así, Criminal es la representación del sueño inquieto de la sociedad, transversal a cualquier intento de espectáculo o de escena blanqueada. Criminal es la escenificación del espeso caudal de cauces heterogéneos que atraviesan la transición, la ciudad, y la poesía chilena.

Pontificia Universidad Católica de Chile* Campus San Joaquín Facultad de Letras Av. Vicuña Mackenna 4860, Macul. Santiago (Chile) lvalenzp@uc.cl 


\section{BIBLIOGRAFÍA}

Atal, Jessica. "En la ruta de la poesía", en diario El Mercurio. 1 de agosto. 1998:3 (Supl.).

Avaria, Antonio. "Bandido chileno no es de jugar", en El Mercurio. 5 de abril, 1997:2. (Supl.).

Berenguer, Carmen. Naciste pintada. Santiago de Chile: Cuarto Propio, 1999.

Beverly, John. Subalternidad y representación. Madrid: Iberoamericana, 2004:23-54.

Calderón, Tatiana. "Cartografía de la ciudad: la casa subversiva en Naciste pintada (1999) de Carmen Berenguer”, en Alpha N²2 (2006):43-55.

Carrasco, Germán. La insidia del sol sobre las cosas. Santiago de Chile: Dolmen, 2003.

Coloma, Marco Antonio. "Yo soy el condenado", en diario El periodista 59, 2004. Consultado: 8 de abril. http://www.elperiodista.cl/newtenberg/1620/article-59954.html.

Corboz, Andrés. "El territorio como palimpsesto", en Ángel Martín Ramos (Ed.). Lo Urbano: 20 autores contemporáneos. Barcelona: UPC, 2004:25-34.

Dammert, Lucía. Violencia criminal y seguridad ciudadana en Chile. Santiago de Chile: CEPAL, 2005.

Dávila, Mireya. Seguridad ciudadana: actores y discusión. Santiago de Chile: FlacsoChile, 2000.

Debord, Guy. Comentarios sobre la sociedad del espectáculo. Barcelona: Anagrama, 2000:9-28.

De Certeau, Michel. "Relatos de espacio", en La invención de lo cotidiano. México: Universidad Iberoamericana, 2000.

Espinosa, Patricia. "Yo soy el peor de los libros", en Rocinante N ${ }^{\circ} 66$ (2004):17.

Franken, Clemens; Sepúlveda, Magda. "El viaje de un género", en Tinta de sangre: narrativa policial chilena en el siglo XX. Santiago de Chile: Universidad Católica Silva Henríquez, 2009:11-18.

Galindo, Óscar. "Marginalidad, subjetividad y testimonio en la poesía chilena de fines de siglo", en Revista de Crítica Literaria Latinoamericana № 58 (2003):193-213.

Genette, Gérad. Umbrales. Buenos Aires: Siglo XXI, 2001.

González, Yanko. Metales Pesados. Valdivia: Kultrún, 1998.

Hachim Lara, Luis. Carlos Pezoa Véliz: alma chilena de la poesía. Valparaíso: Universitarias de Valparaíso, 2005.

Hernández, Biviana. "La casa en la representación interdisciplinaria del discurso: Naciste pintada de Carmen Berenguer", en Taller de Letras $N^{\circ} 43$ (2008):71-87.

Henríquez, Florencia. "Enfermedad crónica o la decepción habitada. Crónica urbana chilena: Imaginarios en torno a la ciudad de Santiago". Tesis de magíster, Pontificia Universidad Católica de Chile, (2008):114-135.

Hobsbawm, Eric. Bandidos. Barcelona: Ariel, 1976.

Kirkpatrick, Gwen. "El lenguaje roído: políticas del poema en Insomnio, Naciste pintada y Naturalismo", en Revista de Crítica Literaria Latinoamericana $\mathrm{N}^{\circ} 65$ (2007):75-85.

Martín-Barbero, Jesús. "La ciudad que median los miedos", en Mabel Moraña. Espacio urbano, comunicación y violencia en América Latina. Pittsburgh: University of Pittsburgh, 2002:18-22.

Masiello, Francine. El arte de la transición. Buenos Aires: Norma, 2001. 
Merino, Roberto. "Microclimas culturales", en Chile en los noventa. Cristián Toloza y Eugenio Labarca (Eds.). Santiago de Chile: Presidencia de la República/Dolmen, (1998):681701.

Mitchell, W.J.T. Teoría de la imagen. Madrid: Akal, 2009.

Morales, Leonidas. "Género y sociedad en las crónicas de Pedro Lemebel”, en Aisthesis $\mathrm{N}^{\circ} 46$ (2009):230-245.

------ La escritura de al lado: Géneros referenciales. Santiago de Chile: Cuarto Propio, 2001.

Moulian, Tomás. Chile Actual. Anatomía de un mito. Santiago de Chile: LOM/Arcis, 1998.

------- “La liturgia de la reconciliación”, en Políticas y estéticas de la memoria. Nelly Richard (Ed.). Santiago de Chile: Cuarto propio, 2000.

Neira, Hernán. “Anestética de Metales Pesados, de Yanko González Cangas”, en Estudios Filológicos $\mathrm{N}^{\circ} 35$ (2000). Obtenido desde http://www.scielo.cl/scielo.php?script=sci_arttext\&pid=S0071$17132000003500014 \& \operatorname{lng}=\mathrm{es} \& n r m=i s o \&$ tlng=es.

Orellana, Carlos. El siglo que vivimos: Chile 1900-1999. Santiago de Chile: Planeta, 1999.

Otano, Rafael. Nueva crónica de la transición. 1995. Santiago de Chile: LOM, 2006.

Pinos, Jaime. Criminal. Santiago de Chile: Libros La Calabaza del Diablo, 2003.

Portes; Roberts. La ciudad bajo el libre mercado: la urbanización en América latina durante los años del experimento neoliberal. Buenos Aires: Prometeo, 2005.

Riffo, Luis. “Criminal'. 2007. Consultado: Noviembre 8. http://www.letras.s5.com/jp080307.htm.

Salinas Campos, Maximiliano. Versos por fusilamiento. El descontento popular ante la pena de muerte en Chile en el siglo XIX. Santiago de Chile: F.C y las Artes, 1993.

Sarlo, Beatriz. "Prefacio". Instantáneas: medios, ciudad y costumbres en el fin de siglo. Buenos Aires: Ariel, 1996:7-10.

Sepúlveda, Magda. "Metáforas de la higiene y la iluminación en la ciudad poetizada bajo el Chile autoritario", en Acta literaria $\mathrm{N}^{\circ} 37$ (2008):67-80.

Subercaseaux, Bernardo. Historia de las ideas y de la cultura en Chile: nacionalismo y cultura. Tomo IV. Santiago de Chile: Universitaria, 2007.

Simunovic Díaz, Horacio. "Estrella distante: Crimen y poesía”, en Acta literaria $\mathrm{N}^{\circ} 33$ (2006):9-25.

Spivak, Gayatri. “¿Puede hablar el sujeto subalterno?”, en Orbis Tertius № 6 (1998):175-235.

Torres, Celedonio. "Jaime Pinos Fuentes: Criminal". Octubre 23, 2009. Consultado: 10 de noviembre.

http://elvendedordetierra.wordpress.com/2009/10/23/jaime-pinos-fuentescriminal/.

White, Hayden. Metahistoria. La imaginación histórica en la Europa del siglo XIX. México: F.C.E., 1992. 